\title{
Study on the effectiveness of navigation safety measures for Nanjing Yangtze River Bridge
}

\author{
Feilong Zhao ${ }^{1, a}$, Guoping Guo ${ }^{2}$ \\ ${ }^{1}$ School of Shipping, Wuhan University of Technology, Wuhan, China \\ ${ }^{2}$ Key Laboratory of Inland Navigation and Hubei Province, Wuhan, China
}

\begin{abstract}
Combined with navigation safety measures such as navigation mark adjustment, synchronous flash distribution, and real ship test adopted by Nanjing Yangtze River Bridge, theoretical analysis methods and data analysis are used to determine the safety evaluation risk index system, and an unascertained measure evaluation model based on entropy weight is constructed. Through the comparison of the effectiveness of the security measures analyzed by the questionnaire, the effectiveness of the bridge safety guarantee measures was evaluated; further suggestions on the optimization of relevant safety protection measures were proposed. The research results are of great significance for maintaining the safety of the bridge, the navigation order of the waters in the bridge area, protecting the navigation resources of the bridge area, and ensuring the navigation safety of the ship.
\end{abstract}

\section{Introduction}

Bridges play an irreplaceable role in promoting economic and social development. However, in the event of a bridge safety incident, the consequences will be unimaginable. Nowadays, more and more bridges are built in the same jurisdiction. It is especially important to carry out the necessary safety guarantees for the safety of the bridge and how to properly solve the problem of water traffic safety in the bridge section. Safety evaluation of the safety measures implemented by the bridge is carried out, and corresponding countermeasures are proposed in time. Through the analysis and evaluation of effectiveness, we can better understand and master the effectiveness of the safety and security measures implemented by the bridge, and provide scientific decision-making basis for the maritime management department to improve the navigation environment and traffic safety of the bridge section and the navigation management and control. And reference, thus having a certain practical value ${ }^{[1]}$.

\section{Brief Introduction to Safety Measures for Navigation in Bridge Area}

In order to ensure the safety of the bridge, the water management department has adopted the following navigation safety guarantee measures, as shown in Table 1 below.

Table 1. Bridge navigation safety protection measures list

\begin{tabular}{|c|c|}
\hline Measure & Effect \\
\hline $\begin{array}{c}\text { Adjusting the } \\
\text { navigation } \\
\text { area of the } \\
\text { bridge area }\end{array}$ & $\begin{array}{c}\text { Guide the ship's driver to accurately identify } \\
\text { the navigation bridge hole and reduce the } \\
\text { drift of the ship. As shown in Figure 1 }\end{array}$ \\
\hline $\begin{array}{c}\text { Navigation } \\
\text { bridge hole } \\
\text { setting buoy } \\
\text { synchronous } \\
\text { flash }\end{array}$ & $\begin{array}{c}\text { The navigation mark of the bridge area is } \\
\text { more obvious, and the ship driver can } \\
\text { correctly follow the navigation mark to } \\
\text { guide the safe navigation through the bridge } \\
\text { area. As shown in Figure 2 }\end{array}$ \\
\hline $\begin{array}{c}\text { Lighting the } \\
\text { navigation } \\
\text { bridge hole }\end{array}$ & $\begin{array}{c}\text { Solved the problem that the crew "can't see } \\
\text { clearly and unclear" about the bridge hole. } \\
\text { As shown in Figure 3. }\end{array}$ \\
\hline $\begin{array}{c}\text { Intelligent } \\
\text { early warning } \\
\text { monitoring }\end{array}$ & $\begin{array}{c}\text { Improve the safe navigation ability of ships } \\
\text { at night and effectively prevent ships from } \\
\text { entering the non-navigate waters }\end{array}$ \\
\hline $\begin{array}{c}\text { Carry out the } \\
\text { 6-hole real } \\
\text { ship test of } \\
\text { the bridge }\end{array}$ & $\begin{array}{c}\text { Through the actual ship test data, the ship's } \\
\text { navigation characteristics are analyzed, the } \\
\text { navigation sign setting is optimized, the ship } \\
\text { navigation method is simulated and } \\
\text { simulated, navigation suggestions are } \\
\text { provided, and the bridge navigation safety is } \\
\text { guaranteed. }\end{array}$ \\
\hline
\end{tabular}

\begin{tabular}{|l|l|} 
No. 1 white buoy $\bigcirc$ & No.1 red buoy \\
No. 2 white buoy $\bigcirc$ & No. 2 red buoy \\
No. 3 white buoy $\bigcirc$ & No. 3 red buoy \\
\hline
\end{tabular}

\footnotetext{
a Corresponding author: 15171456122@163.com
} 
Figure 1. Schematic diagram of the adjustment scheme for the navigation mark hole navigation mark

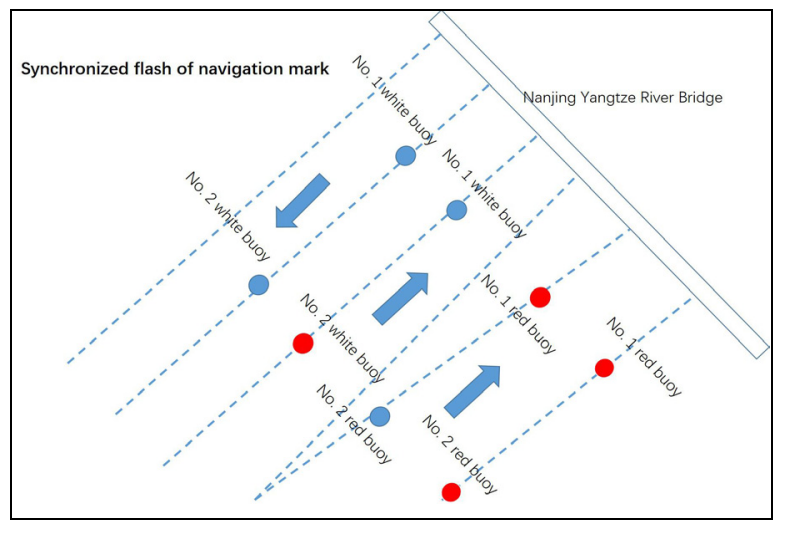

Figure 2. Schematic diagram of synchronous flash distribution scheme.

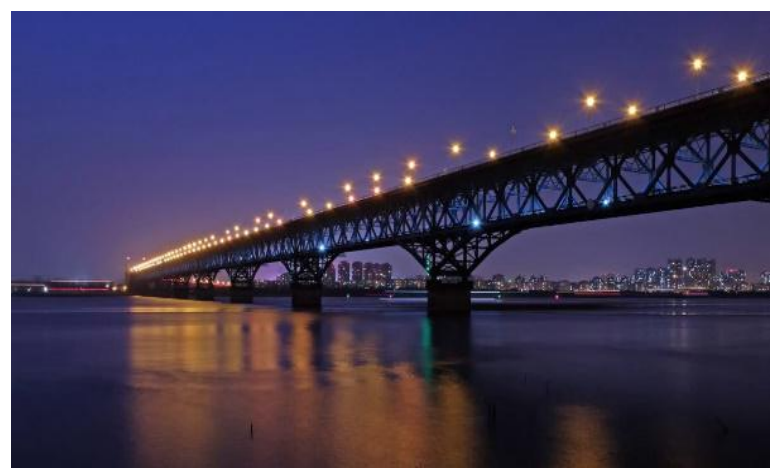

Figure 3. Schematic diagram of the distribution scheme of the navigation bridge hole lighting.

\section{Safety Benefit Evaluation of Bridge Safety Protection Measures}

\subsection{Safety Benefit Evaluation of Bridge Segment}

Establish a safety assessment risk indicator system for this jurisdiction, including people, ships, bridges, environment, and management, with a total of 26 secondary evaluation indicators. The expert judgment method is used to construct the comparative judgment matrix of the evaluation index. The brainstorming method is used to determine the membership degree of each index. Finally, the center of gravity method is used to defuzzify and obtain the comprehensive evaluation score of each index ${ }^{[2]}$. Five fuzzy comments were expressed for the safety benefits, and finally the effectiveness of the bridge safety guarantee measures was judged.

\subsection{Unascertained measure evaluation model based on entropy weight}

\subsubsection{Single indicator not determined calculation}

The calculation of the single-index unascertained measure matrix uses the method of constructing the unascertained measure function, and is determined by the expert scoring method. According to the characteristics of the specific problem to be solved and the severity of the state change, the undetermined measure function can be connected by different curves such as a straight line and a quadratic curve ${ }^{[3]}$. Among them, the linear unascertained measure function is currently the most widely used. Its calculation formula is as follows:

$$
\begin{gathered}
\mu\left(x \in c_{k+1}\right)=\frac{-x}{a_{i}+1}+\frac{a_{i+1}}{a_{i+1}-a_{i}} a_{i}<x<a_{i+1} \\
\mu\left(x \in c_{k+1}\right)=x>a_{i+1}
\end{gathered}
$$

Among them, $\boldsymbol{a}_{\boldsymbol{i}}$ is the classification standard of each indicator, and $\boldsymbol{C}_{\boldsymbol{k}}$ is the evaluation level. From the calculation formula (1) (2), it can be concluded that the observation value $\boldsymbol{x}_{\boldsymbol{i}}$ of the index $\boldsymbol{I}_{\boldsymbol{j}}$ with respect to the index $x_{i j}$ causes the object to be in the single-index unsure degree matrix of each evaluation level $\boldsymbol{C}_{\boldsymbol{k}}$ as follows:

$$
\begin{gathered}
\left(u_{i j k}\right)_{m \times k}=\left[\begin{array}{cccc}
u_{i 12} & u_{i 12} & \cdots & u_{i 1 k} \\
u_{i 21} & u_{i 22} & \cdots & u_{i 2 k} \\
\cdots & \cdots & \cdots & \cdots \\
u_{i m 1} & u_{i m 2} & \cdots & u_{i m k}
\end{array}\right] \\
i=1,2, \cdots, n ; j=1,2, \cdots m ; k=1,2, \cdots K
\end{gathered}
$$

\subsubsection{Entropy weight method weight calculation}

Entropy is a measure of the uncertainty of the state of the system. The index weight assignment method based on entropy weight is a combination of quantitative and qualitative methods, which expresses and processes human subjective judgments in quantitative form ${ }^{[4]}$. Calculate the measure value of the evaluation index according to the corresponding membership function to construct $\left(\mu_{i 1}, \mu_{i 2}, \mathrm{~L}, \mu_{i 1}\right)$, The entropy is now:

$$
\begin{aligned}
& H=-\frac{1}{\log _{10} k} \sum_{k=1}^{k} u_{i j k} \log _{10} u_{i j k} \\
& v_{i j}=1+\frac{1}{\log _{10} k} \sum_{k=1}^{k} u_{i j k} \log _{10} u_{i j k}
\end{aligned}
$$

Obviously, $0 \leqslant u_{i j k} \leqslant 1$ let:

$$
w_{i j}=v_{i j} / \sum_{j=1}^{m} v_{i j}
$$

The weight $w_{i}=\left(w_{i 1}, w_{i 2}, \cdots, w_{i m}\right)^{T}$ is used as the weight vector of the attribute set $U$, that is, its entropy weight. Where $\mathrm{H}$ is the entropy value of the evaluation index; $v_{i j}$ is the proportion of the $\mathrm{j}$-th evaluation object in the i-th indicator.

\subsubsection{Multi-indicator comprehensive measure calculation}


Table 5. Indicator value vector

\begin{tabular}{|c|c|c|c|c|}
\hline \multicolumn{5}{|c|}{ Measure vector } \\
\hline $\mathrm{C} 1$ & $\mathrm{C} 2$ & $\mathrm{C} 3$ & $\mathrm{C} 4$ & $\mathrm{C} 5$ \\
\hline 0 & 0 & 0 & 0.175 & 0.825 \\
\hline 0 & 0 & 0 & 0.150 & 0.850 \\
\hline 0 & 0 & 0 & 0.175 & 0.825 \\
\hline 0 & 0.100 & 0.125 & 0.200 & 0.575 \\
\hline 0 & 0 & 0 & 0.100 & 0.900 \\
\hline 0 & 0 & 0.050 & 0.125 & 0.825 \\
\hline 0 & 0 & 0.050 & 0.175 & 0.775 \\
\hline 0 & 0 & 0.075 & 0.125 & 0.800 \\
\hline
\end{tabular}

According to the entropy weight calculation formula (4) described above, the calculated values of the entropy weights of each evaluation index can be obtained as follows:

$\mathrm{H}_{\mathrm{V} 11}=-\frac{1}{\lg 5}(0+0+0+0.175 * 0.0825)=0.288$

In the same way, the calculation is:

$\mathrm{H}_{\mathrm{v} 12}=0263, \mathrm{H}_{\mathrm{v} 13}=0.288, \mathrm{H}_{\mathrm{v} 14}=702, \mathrm{H}_{\mathrm{v} 21}=0.202$;

$\mathrm{H}_{\mathrm{v} 31}=405, \mathrm{Hv}_{3} 2=393$;

therefore, $\mathrm{HV}_{\mathrm{V}}=(0.288,0.263,0.288,0.702)$,

$\mathrm{H}_{\mathrm{V} 2}=(0.202,0.353), \mathrm{H}_{\mathrm{V} 3}=(0.405,0.393)$;

According to formula (5), it can be calculated:

$\mathrm{V}_{\mathrm{U} 1}=(0.712,0.737,0.712,0.298) ;$ In the same way,

$\mathrm{V}_{\mathrm{U} 2}=(0.798,0.647) ; \mathrm{V}_{\mathrm{U}} 3=(0.595,0.607)$;

Calculate the entropy weight of each indicator according to formula (6):

$\mathrm{W}_{\mathrm{U} 1}=(0.289,0.300,0.289,0.121)$

In summary, the calculation results of the entropy weight of each of the secondary indicators and the primary indicators are shown in Table 6.

Table 6. Index entropy weight calculation result

\begin{tabular}{|c|c|c|c|}
\hline \multirow{2}{*}{$\begin{array}{c}\text { Primary } \\
\text { factor }\end{array}$} & Weights & $\begin{array}{c}\text { Secondary evaluation } \\
\text { factor }\end{array}$ & Weights \\
\hline \multirow{2}{*}{ Ship } & \multirow{2}{*}{0.300} & $\begin{array}{c}\text { Improvement effect of } \\
\text { dangerous goods ship } \\
\text { accident }\end{array}$ & 0.289 \\
\cline { 3 - 4 } & & $\begin{array}{c}\text { Ship sailing freely to } \\
\text { improve the effect }\end{array}$ & 0.300 \\
\cline { 3 - 4 } & $\begin{array}{c}\text { Improve the effect of } \\
\text { crossing the traffic lane }\end{array}$ & 0.289 \\
\cline { 3 - 4 } & $\begin{array}{c}\text { Improved navigational } \\
\text { safety index }\end{array}$ & 0.121 \\
\hline \multirow{2}{*}{ envirnmental } \\
factor
\end{tabular}

\subsection{Bridge safety evaluation}

\subsubsection{Single indicator unascertained degree calculation}

The evaluation results were processed by the mean value analysis method to obtain the scores of the respective indexes, as shown in Table 7.

Table 7. Effectiveness evaluation indicator score

\begin{tabular}{|c|c|c|c|}
\hline $\begin{array}{l}\text { Primary } \\
\text { evaluation } \\
\text { factor }\end{array}$ & \multicolumn{2}{|c|}{ Secondary evaluation factor } & Score \\
\hline \multirow{4}{*}{ Ship factor } & \multicolumn{2}{|c|}{$\begin{array}{l}\text { Improvement effect of dangerous } \\
\text { goods ship accident }\end{array}$} & 93.25 \\
\hline & \multicolumn{2}{|c|}{$\begin{array}{l}\text { Ship sailing freely to improve the } \\
\text { effect }\end{array}$} & 93.50 \\
\hline & \multicolumn{2}{|c|}{$\begin{array}{l}\text { Improve the effect of crossing the } \\
\text { traffic lane }\end{array}$} & 93.25 \\
\hline & \multicolumn{2}{|c|}{ Improved navigational safety index } & 87.5 \\
\hline \multirow{8}{*}{$\begin{array}{l}\text { envirnmental } \\
\text { factor }\end{array}$} & \multirow{4}{*}{$\begin{array}{c}\text { Natural } \\
\text { environment }\end{array}$} & Wind direction & \multirow{4}{*}{94.00} \\
\hline & & Flow rate & \\
\hline & & Visibility & \\
\hline & & water depth & \\
\hline & \multirow{4}{*}{$\begin{array}{c}\text { Traffic } \\
\text { environment }\end{array}$} & $\begin{array}{l}\text { Navigation aid } \\
\text { sign }\end{array}$ & \multirow{4}{*}{92.75} \\
\hline & & Obstruction & \\
\hline & & traffic flow & \\
\hline & & Wind direction & \\
\hline \multirow{2}{*}{$\begin{array}{l}\text { Management } \\
\text { factor }\end{array}$} & \multicolumn{2}{|c|}{$\begin{array}{l}\text { Bridge area water safety protection } \\
\text { facilities }\end{array}$} & 92.25 \\
\hline & \multicolumn{2}{|c|}{ First aid to improve the effect } & 92.25 \\
\hline
\end{tabular}

From the definition of the single-index measure function, an image of the single-index unascertained function of each index risk assessment can be obtained, as shown in Figure 4.

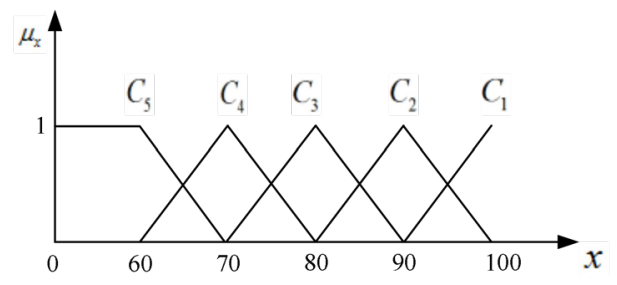

Figure 4. The unascertained measure function

The values of the indicators in Table 7 are respectively taken into the single-index measure function, and the single-index evaluation matrix for the safety and effectiveness evaluation of the safeguard measures is calculated ${ }^{[6]}$.

Taking the "improvement effect of dangerous goods ship accident" in the ship factor as an example, according to the score value of Table 7, Figure 5 and formula (1). (2) and the "normality" of the unascertained measure, it can be concluded that The single-index measure vector that separates the opposite traffic flow to reduce the effect on the situation is $\left(\begin{array}{llllll}0 & 0 & 0 & 0.675 & 0.325\end{array}\right)$. The same method can be used to find the unascertained measure of other indicators.

According to the calculation, the unascertained measure evaluation matrix of the ship safety factor for safety and safety measures is: 


$$
\mu_{15}=\left[\begin{array}{ccccc}
0 & 0 & 0 & 0.675 & 0.325 \\
0 & 0 & 0 & 0.650 & 0.350 \\
0 & 0 & 0 & 0.675 & 0.325 \\
0 & 0 & 0.25 & 0.750 & 0
\end{array}\right]
$$

The unascertained measure evaluation matrix for environmental factors is:

$$
\mu_{25}=\left[\begin{array}{lllll}
0 & 0 & 0 & 0.600 & 0.400 \\
0 & 0 & 0 & 0.725 & 0.275
\end{array}\right]
$$

The unascertained measure evaluation matrix for management factors is:

$$
\mu_{35}=\left[\begin{array}{lllll}
0 & 0 & 0 & 0.675 & 0.325 \\
0 & 0 & 0 & 0.675 & 0.325
\end{array}\right]
$$

\subsubsection{Multi-indicator unascertained degree calculationcalculation}

The single indicator measure vector of the ship factor in the safety effectiveness assessment of the bridge navigation safety measures is:

$$
\begin{gathered}
\mu_{11}=\omega_{1} \times \mu_{15} \\
=\left(\begin{array}{lllll}
0.289 & 0.300 & 0.289 & 0.121
\end{array}\right) \times\left[\begin{array}{ccccc}
0 & 0 & 0 & 0.675 & 0.325 \\
0 & 0 & 0 & 0.650 & 0.350 \\
0 & 0 & 0 & 0.675 & 0.325 \\
0 & 0 & 0.25 & 0.750 & 0
\end{array}\right]
\end{gathered}
$$

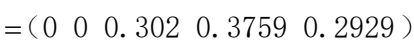

By repeating the above calculations in the same way, the single-index unascertained measure vectors of the ship, environment and management factors in the safety and effectiveness assessment of the bridge navigation safety measures can be obtained as follows:

$$
\begin{aligned}
& \mu_{22}=\left(\begin{array}{llllll}
0 & 0 & 0 & 0.6560 & 0.3440
\end{array}\right) \\
& \mu_{33}=\left(\begin{array}{lllll}
0 & 0 & 0 & 0.6750 & 0.3250
\end{array}\right)
\end{aligned}
$$

Therefore, a new unascertained matrix " $\mu$ " can be constructed. According to formula (7), the multi-indicator unascertained comprehensive measure "" $\mu$ " " for the safety and effectiveness evaluation of the bridge navigation safety measures can be calculated.

$$
\begin{gathered}
\mu=\omega \times \mu_{1} \\
=\left(\begin{array}{lll}
0.300 & 0.380 & 0.320
\end{array}\right) \times\left[\begin{array}{ccccc}
0 & 0 & 0.0302 & 0.6759 & 0.2929 \\
0 & 0 & 0 & 0.6560 & 0.3440 \\
0 & 0 & 0 & 0.6750 & 0.3250
\end{array}\right]
\end{gathered}
$$

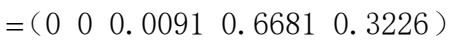

\subsubsection{Bridge safety assessment conclusion}

According to the comprehensive measure calculated above, using the formula (7) to identify the multiindicator comprehensive measure of the safety and effectiveness assessment of the bridge safety guarantee measures ${ }^{[7]}$, the following conclusions can be drawn: a. $\mathrm{k}_{0}=1$, at this time there is 0.6681 for maximum integration and greater than 0.66 . If it is taken $\lambda=0.66$, there is $\mathrm{k}_{0}=1,0.6681>\lambda$, that is, the safety effectiveness evaluation level of the bridge navigation safety measure belongs to the "Great effect" level, and the confidence level is not less than $66 \%$.

b. $\mathrm{k}_{0}=2$, at this time there is $0.6681+0.3226=0.9907$.

If it is taken $\lambda=0.99$, there is $\mathrm{k}_{0}=1,0.9907>\lambda$, that is, the safety effectiveness evaluation level of the bridge navigation safety protection measure belongs to the "Greater effect" level, and the confidence level is not less than $99 \%$.

\section{Research conclusions and prospects}

This paper takes the various security measures adopted by the Nanjing Yangtze River Bridge as the research object, and uses theoretical analysis methods and questionnaire survey data to evaluate the implementation effectiveness of the bridge navigation safety guarantee measures for the navigation environment of the bridge area of the Nanjing Yangtze River Bridge, and analyze the Nanjing Yangtze River. The safety benefits brought by the bridge in terms of ensuring the safety of the navigation of the ship, the smooth flow of the channel ${ }^{[8]}$, and the construction of the port are finally evaluated to evaluate the effectiveness of the safety measures for the navigation of the bridge; further recommendations for the optimization of relevant safety measures are proposed. The research results are of great significance for maintaining the safety of other bridges, the navigation order of ships in the bridge area, protecting the navigation resources of the bridge area, and ensuring the navigation safety of the ships. It is of great significance to the development of the Yangtze River trunk shipping and the sustainable development of the port water transport economy. At the same time, it can provide suggestions for maritime affairs and related departments, which has certain practical significance for improving the safety of the bridge.

\section{References}

1 Qiang.Gao Research on Risk Assessment of Water Traffic Safety in Multi-Bridge Reach. (2010501 Wuhan University of Technology)

2 "Guidelines for the Implementation of Navigation Safety Responsibilities by Bridge Management Units"

3 "Nanjing Yangtze River Bridge Bridge Area Water Navigation Guide". (Nanjing Maritime Safety Bureau issued in 2018)

4 Jiani.Zhao Overview of the Comprehensive Safety Assessment (FSA) method. Navigation Technology, 2005 (2): 77-78

5 Yansheng.Han Research on Yangtze River water traffic safety evaluation index system [D]. Wuhan: Wuhan R\&D University, April 2006 
6 Jinsong.Zhao Ship-bridge collision and anti-collision problem of Nanjing Yangtze River Bridge [J]. Journal of Dalian Maritime University, 1992(1): 77 81

7 Silveira P A M, Teixeira A P, Guedes S C. Use of AIS Data to Characterise Marine Patterns and Ship Collision Risk offthe Coast of Portugal[J].Journal of Navigation, 2013, 66(6):879-898.
8 Zhong Wei. Current Status and Reform Suggestions for Navigation Safety Maintenance of Local Maritime Underwater Activities[J]. China Water Transport, 2018(11): 42-43. 